\title{
Prevalence of pathogenic bacteria in meat products and their antimicrobial resistance pattern
}

\author{
Madhup Surendra Kumar ${ }^{1,2}$, Shrestha Rashmi ${ }^{3}$, Panta Rakshya ${ }^{3}$, Chauguthi Laxmi ${ }^{4}$, \\ Katuwal Nishan ${ }^{4}$, Shrestha Sunaina ${ }^{2}$
}

\author{
Affiliations: \\ ${ }^{1}$ Department of Microbiology, School of Medical Sci- \\ ences, Kathmandu University \\ ${ }^{2}$ Department of Microbiology, Dhulikhel Hospital, \\ Kathmandu University Hospital \\ ${ }^{3}$ School of Medical Sciences, Kathmandu University \\ ${ }^{4}$ Research and Development Division, Dhulikhel Hos- \\ pital
}

\section{Correspondence to:}

Surendra Kumar Madhup

Lecturer, Department of Microbiology, School of Medical Sciences, Kathmandu University

Phone: +977-9801002249

Email: sur2036@hotmail.com

Received: 6 August, 2021 Accepted: 10 Nov, 2021

How to cite this Article:

Madhup SK, Shrestha R, Panta R, Chauguthi L, Katuwal N, Shrestha S. Prevalence of pathogenic bacteria in meat products and their antimicrobial resistance pattern. Ann. Clin. Chem. Lab. Med. 2021:4(1); 13-19

DOI: https://doi.org/10.3126/acclm.v4i1.42676

\section{(C) 2022 Nepalese Association for Clinical Chemistry}

\section{(D)}

This work is licensed under a Creative Commons Attribution-Share Alike 4.0 International License.

\begin{abstract}
\section{BACKGROUND}

There is increase in consumption of antimicrobial agents with misuse and/or overuse of antimicrobial agents in animals and resulting to rise in antimicrobial resistance. The controlled use of antimicrobials is important for national and international policymakers to draw guidelines on its use. Assessing AMR in meatproducing industry is essential to track emerging resistant pathogens that are common between animals and humans. In this study, we have aimed to investigate the prevalence of bacteria in meat products and the antimicrobial resistance pattern in those isolates.
\end{abstract}

\section{METHODS}

This study is a quantitative, observational study, where we collected meat samples $(n=118)$ from shops, in Banepa and Dhulikhel Municipality. The samples were cultured in appropriate media for isolation of bacteria. Subsequently, AMR pattern was studied through antibiotic susceptibility test using Kirby Bauer Disc Diffusion method.

\section{RESULTS}

In our study, only two sites, out of 48 , did not have any pathogenic bacteria. There were total of 113 isolates from 118 samples. E.coli (62.8\%), Enterococcus $(14.1 \%)$, Klebsiella pneumoniae $(11.5 \%)$,were the most prevalent bacteria in processed samples including MRSA (4\%). Additionally, $81.6 \%$ of the isolated E.coli were resistant to Ampicillin and $60.5 \%$ to Ciprofloxacin and $35 \%$ to Gentamycin. $43.6 \%$ of all isolated E. coli, $100 \%$ of all Klebsiella, $100 \%$ of all Enterobacterand $25 \%$ of all Citrobacter were multidrug resistant.The resistance was mostly observed against Ampicillin (83.3\%), followed by resistance against Ciprofloxacin (64.4\%), Gentamycin (58.8\%), Ceftazidime $(38.8 \%)$, with the lowest resistance against Sulbactam/Cefoperazone (3.3\%)

\section{CONCLUSION}

$E$. coli was the most prevalent organism in meat samples. Multi-drug resistancewas also most common in E.coli with resistance against Ampicillin, Ciprofloxacin and Gentamycin. Therefore, we recommend for more controlled use of antibiotics in animal rearing industry and more hygienic environment at meat vendors

\section{KEY WORDS:}

Antimicrobial resistance, antibiotics, MDR, meat 


\section{INTRODUCTION}

Antibiotics are one of the major drugs that have been used for treatment of infectious diseases for over five decades. ${ }^{1}$ The major applications of antibiotics include medicine for human as well as veterinary health. ${ }^{2}$ Particularly, they can also be used on agriculture and veterinary for increasing feed efficiency, growth improvement in addition to control, prevention and treatment of infections. ${ }^{3}$ Antibiotics are also vastly used to reduce mortality in veterinary and as a growth promoter. ${ }^{4}$ By 2030 , the global consumption for antimicrobials in the food animal production system is estimated to increase upto 105,596 metric tonnes. ${ }^{5}$ The use of antimicrobials is four times higher in animals than in humans. ${ }^{6}$ These antimicrobials are administered without much awareness or formal education, leading to misuse and incorrect dosages. $^{7}$

Various studies have covered the misuse of antibiotics, particularly in the meat rearing industry. For instance, a study has shown the use of oxytetracycline (OTC) to prevent transit fever caused by Pasteurella multocida, in animals during their transportation. ${ }^{8}$ A study in Morogoro, $90 \%$ of broiler farmers frequently used tetracycline, amprolium, sulphonamides, trimethoprim, neomycin and flumequine in their chicken flocks. ${ }^{9,10}$ Similarly, another study has reported the presence of antimicrobials reissued in $76.4 \%$ of broiler meat samples. $^{10}$

These antibiotic residues in food products could adversely affect the health through allergic reactions, carcinogenicity, hepatotoxicity, neuropathy and antibacterial resistance. ${ }^{11}$ For instance, the use of antimicrobials in food animals result in selection of resistance pathogens as well as transfer of the resistance gene to humans through handling or consumption. Additionally, studies have demonstrated that resistance among foodborne bacteria may result in increased rate of bacteremia, prolonged illness, hospitalization and even death. ${ }^{12}$ One of the major causative agents for these foodborne illness are bacteria and among them Salmonella spp., Staphylococcus aureus, Enterobacteriaceae, including Escherichia coli(E. coli) make upto $40 \%$ of the bacterial attributed foodborne illness. ${ }^{13,14}$ Although, it has been documented that cooking temperatures can destroy the foodborne bacteria and antimicrobial residues, particularly in meat, inadequately cooked meat could cause adverse drug reaction and development of antimicrobial resistance. ${ }^{15}$

An increasing trend of antimicrobial misuse can be seen in Nepal as well, mostly in meat industry as this industry has enlarged with the growing middle class. For instance, poultry production represents $4 \%$ of Nepal's gross product, as of $2017 .{ }^{16}$ A study in Kathmandu Valley, depicted $90 \%$ prevalence of antibiotics use, either as a therapeutic or as prophylaxis. ${ }^{17}$ In a study, it was found that $67 \%$ of the poultry producer had little or negligible knowledge on AMR. ${ }^{18}$ Another study, depicted $46 \%$ of veterinary drugs were sold under self-prescription. ${ }^{4}$ And, the producers or farmers are known to use antibiotics to compensate poor farm sanitation. ${ }^{18-20}$ The products of such industry would harbordrug resistant bacteria. For instance, Escherichia coli strains resistant to amoxicillin + clavulanate, sulphamethoxazole and neomycin, Methicillin Resistant Staphlococcus aureus (MRSA) and Extended-Spectrum BetaLactamase (ESBL) is also found in the livestock sector. ${ }^{8}$ Similarly, in Nepal, a study observed the presence of 103 gram-negative bacteria isolated from 38 meat samples. ${ }^{21}$ Citrobacter species, Salmonella species, Proteus species, E. coli, Pseudomonas species andKlebsiella species were seen, where E. coli showed resistance of Ampicillin followed by Colistin and Polymyxin B. ${ }^{21}$ Similarly, another study in Nepal, showed presence of E. coli, Klebsiella, Citrobacter, Staphylococcus and Salmonella in raw meats. ${ }^{22}$ The highest resistance was againstAmoxicillin followed by Tetracycline, Cotrimoxazole and Nalidixic acid.

Therefore, in this study, we aim to investigate the presence foodborne illness causing microorganisms in raw meat, along with their antibiotic resistance pattern. We expect the dissemination of our results would lead to improved hygiene among the meat vendors and updated regulations and guidelines for the use of antimicrobial drugs in veterinary field.

\section{METHOD}

Sampling Site and Collection:

In this study, meat samples from chicken, goat and buffalo were collected from 48 different shops. The samples collected in sterile plastic containers and brought to Microbiology Laboratory. The meat samples included intestine, 
liver and other parts.

\section{Microbiological Culture:}

The meat samples were minced and inoculated in BHI broth (CM1135B) for 18-24 hours at $37^{\circ} \mathrm{C}$. After the incubation, the samples were then sub-cultured in Columbia Blood Agar (CM0331B), Xylose Lysine Deoxycholate Agar (XLD) (CM0469B) and MacConkey Agar (CM0007B).

\section{Confirmation of Culture:}

After the observation of any growth, gram staining and appropriate biochemical tests were performed using media from OXOID Inc on each colony. The observation of Gram Positive Cocci (GPC) type colonies were not investigated further, as they did not add to the objectives of the study.

\section{Antibiotic Susceptibility Tests:}

Subsequently, antibiotic susceptibility tests were done using appropriate antibiotics (from OXOID Inc.), using Kirby Bauer Disc Diffusion method. The zone of inhibition was measured and the results were evaluated as Resistant (R), Sensitive (S) and Intermediate (I). The organism that showed resistance to three or more groups of antibiotics were termed as Multi-Drug Resistant (MDR). ${ }^{23}$ All the microbiological activities in this study adhere to Clinical \& Laboratory Standards Institute (CLSI) guidelines. ${ }^{24}$

\section{RESULTS}

In this study, there were total of 118 meat samples from 48 different sites.

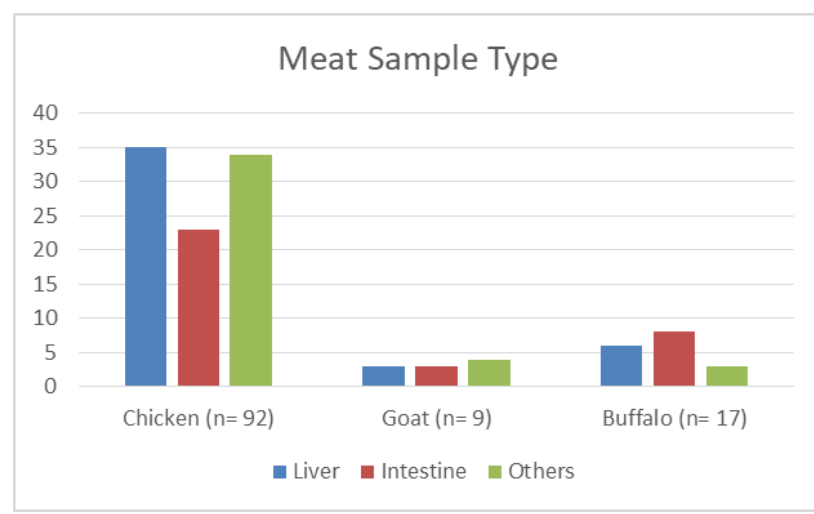

Figure 1: The number of samples in each meat type for each meat source (chicken $=92$ samples, goat $=9$ samples and buffalo $=17$ samples).

Out of 48 sites, only two (4.16\%) did not have any pathogenic bacterial isolates. And, out of the 118 different samples, a total of 113 iso- lates were identified. The types of isolates after characterization have been presented below:

Figure 2: Details of the total isolates $(n=113)$ and their distribution

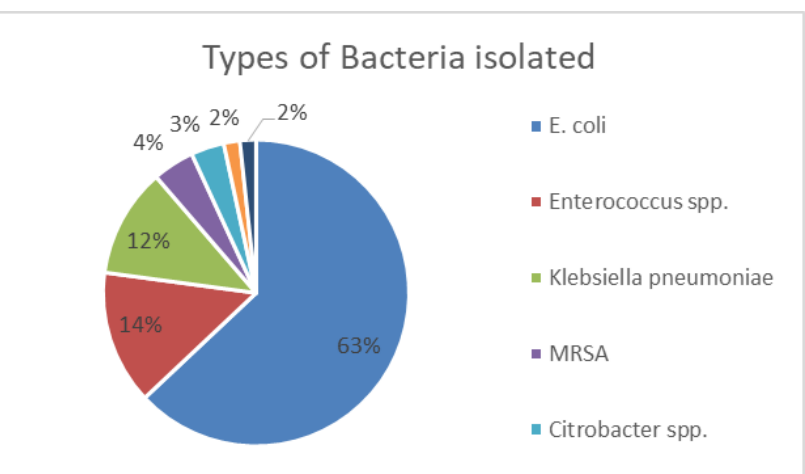

Each meat source also had different types and numbers of organism isolated. For instance, 86 organisms were isolated from chicken meat, while 12 were isolated from goat and 15 from buffalo meat.

Table 1: Details on total meat samples with number of samples that did not show any growth of bacteria

\begin{tabular}{c|c|c|}
\hline Sample Type & $\begin{array}{c}\text { Total Samples } \\
\text { Taken }\end{array}$ & $\begin{array}{c}\text { Samples without } \\
\text { any pathogenic } \\
\text { isolates }\end{array}$ \\
\hline Chicken & 92 & 14 \\
\hline Goat & 9 & 0 \\
\hline Buffalo & 17 & 3 \\
\hline
\end{tabular}

Table 2: The distribution of total isolates $(n=113)$ among meat source

\begin{tabular}{l|l|l|l|}
\cline { 2 - 4 } $\begin{array}{l}\text { Name of } \\
\text { organisms }\end{array}$ & $\begin{array}{l}\text { Chicken } \\
(\mathbf{n}=\mathbf{8 6})\end{array}$ & $\begin{array}{l}\text { Goat } \\
(\mathbf{n = 1 2})\end{array}$ & $\begin{array}{l}\text { Buffalo } \\
(\mathbf{n}=\mathbf{1 5})\end{array}$ \\
\hline E. coli & 60 & 5 & 6 \\
\hline $\begin{array}{l}\text { Enterococcus } \\
\text { spp. }\end{array}$ & 9 & 4 & 3 \\
\hline K pneumoniae & 9 & & 4 \\
\hline MRSA & 2 & 2 & 1 \\
\hline Citrobacter spp. & 4 & & \\
\hline $\begin{array}{l}\text { Enterobacter } \\
\text { spp. }\end{array}$ & 1 & 1 & \\
\hline MSSA & 1 & 1 & \\
\hline
\end{tabular}


Similarly, the antibiotic resistance pattern of each of the isolates and number of resistant isolates have been presented below:

Table 3: Details of antibiotic resistance pattern of gram-negative bacterial isolates.

\begin{tabular}{|c|c|c|c|c|}
\hline $\begin{array}{l}\text { Antibiotic/ } \\
\text { Organisms }\end{array}$ & E. $\operatorname{coli}(n=71)$ & $\begin{array}{l}\text { Klebsiella pneumoniae } \\
\qquad(\mathrm{n}=13)\end{array}$ & $\begin{array}{l}\text { Citrobacter spp. } \\
\qquad(\mathrm{n}=4)\end{array}$ & $\begin{array}{l}\text { Enterobacter spp. } \\
\qquad(\mathrm{n}=2)\end{array}$ \\
\hline $\mathrm{AK}$ & $19(26.7 \%)$ & $12(92.3 \%)$ & & $2(100 \%)$ \\
\hline \multicolumn{5}{|l|}{$\mathrm{AMC}$} \\
\hline AMP & $58(81.6 \%)$ & $13(100 \%)$ & $2(50 \%)$ & $2(100 \%)$ \\
\hline CFP & $16(22.5 \%)$ & $13(100 \%)$ & $1(25 \%)$ & $2(100 \%)$ \\
\hline CIP & $43(60.5 \%)$ & $12(92.3 \%)$ & $2(50 \%)$ & $2(100 \%)$ \\
\hline $\mathrm{CN}$ & $37(52.1 \%)$ & $13(100 \%)$ & $1(25 \%)$ & $2(100 \%)$ \\
\hline \multicolumn{5}{|l|}{ COT } \\
\hline \multicolumn{5}{|l|}{ COX } \\
\hline CTR & $17(23.9 \%)$ & $12(92.3 \%)$ & & $2(100 \%)$ \\
\hline CTZ & $21(29.5 \%)$ & $12(92.3 \%)$ & & $2(100 \%)$ \\
\hline \multicolumn{5}{|l|}{ CXM } \\
\hline \multicolumn{5}{|l|}{ DA } \\
\hline \multicolumn{5}{|l|}{$\mathrm{E}$} \\
\hline IPM & $10(14.0 \%)$ & $11(84.6 \%)$ & & $2(100 \%)$ \\
\hline $\mathrm{LZ}$ & & & $1(25 \%)$ & $2(100 \%)$ \\
\hline MRP & $10(14.0 \%)$ & $10(76.9 \%)$ & & \\
\hline \multicolumn{5}{|l|}{$\mathrm{P}$} \\
\hline $\mathrm{SCF}$ & $2(2.8 \%)$ & & & $1(50 \%)$ \\
\hline \multicolumn{5}{|l|}{ TEC } \\
\hline TZP & $5(7.0 \%)$ & $9(69.2 \%)$ & & $2(100 \%)$ \\
\hline VA & & & & \\
\hline
\end{tabular}

AMP: Ampicillin, CFP: Cefoperazone, SCF: Sulbactam/Cefoperazone, CTR: Ceftriaxone, CIP: Ciprofloxacin, CN: Gentamycin, IPM: Imipenem, MRP: Meropenem, PTZ: PiperacillinTazobactam, AK: Amikacin, P: Penicillin, CIP: Ciprofloxacin, VA: Vancomycin, TE: Teicoplanin, LZ: Linezolid, CTZ: Ceftazidime; COX: Cloxacillin, DA: Clindamycin, E: Erythromycin, COT: Cotrimoxazole, CXM: Cefixime, CN: Gentamycin, AMC: Amoxyclave.

\section{DISCUSSION}

Out of the 48 sites, from where the samples were collected, only two sites did not contain any pathogenic bacteria. Based on the type of bacteria isolated, the results suggests the lack of hygiene in most of the sites where the meat was sold.

There were total of 113 isolates from 118 samples. Buffalo meat $(n=3)$ and chicken meat $(n=14)$ had samples without growth of any bacteria. number of isolates per sample was highest for goat meat. This result is in contrast to another study, in Bhaktapur, which showed higher percentage of isolates in buffalo meat $(95.7 \%){ }^{22}$ This difference in observation could indicate the difference of hygiene in the meat vendors in Bhaktapur and Kavre. The results from our study suggests that goat meat is the most bacterial-infested meat source type. Interestingly, no any MDR bacteria were seen in samples from goat meat. However, chicken meat had total of 40 MDR bacteria (46.5\%) among the bacteria isolated. Though only 7 MDR bacteria were isolated from buffalo meat, the 
meat, the percentage of isolation of MDR $(46.6 \%)$ was similar to chicken. From these results, the argument on which type of meat is safer is ambiguous . Chicken meat $(15.2 \%)$ and buffalo meat $(17.6 \%)$ had similar percentage of samples without any bacterial infestation. However, though, the goat meat did not have any MDR isolates, the presence of non-MDR isolates was highest in it.

Table 4: Details of antibiotic resistance pattern of gram-positive bacterial isolates.

\begin{tabular}{|c|c|c|}
\hline $\begin{array}{c}\text { Antibiotics and } \\
\text { Organisms }\end{array}$ & $\begin{array}{l}\text { Enterococcus } \\
\text { spp. }(n=16)\end{array}$ & $\mathrm{SA}(\mathrm{n}=7)$ \\
\hline \multicolumn{3}{|l|}{$\mathrm{AK}$} \\
\hline $\mathrm{AMC}$ & & $3(42.86 \%)$ \\
\hline \multicolumn{3}{|l|}{ AMP } \\
\hline \multicolumn{3}{|l|}{ CFP } \\
\hline CIP & $6(37.5 \%)$ & $3(42.86 \%)$ \\
\hline $\mathrm{CN}$ & & $3(42.86 \%)$ \\
\hline COT & & $3(42.86 \%)$ \\
\hline $\mathrm{COX}$ & & $3(42.86 \%)$ \\
\hline \multicolumn{3}{|l|}{ CTR } \\
\hline \multicolumn{3}{|l|}{ CTZ } \\
\hline CXM & & $3(42.86 \%)$ \\
\hline $\mathrm{DA}$ & & $3(42.86 \%)$ \\
\hline $\mathrm{E}$ & & $3(42.86 \%)$ \\
\hline \multicolumn{3}{|l|}{ IPM } \\
\hline $\mathrm{LZ}$ & $1(6.2 \%)$ & $2(28.57 \%)$ \\
\hline \multicolumn{3}{|l|}{ MRP } \\
\hline $\mathrm{P}$ & $4(25 \%)$ & $3(42.86 \%)$ \\
\hline \multicolumn{3}{|l|}{ SCF } \\
\hline TEC & $1(6.2 \%)$ & \\
\hline \multicolumn{3}{|l|}{$\mathrm{TZP}$} \\
\hline VA & $3(18.7 \%)$ & \\
\hline
\end{tabular}

AMP: Ampicillin, CFP: Cefoperazone, SCF: Sulbactam/Cefoperazone, CTR: Ceftriaxone, CIP: Ciprofloxacin, CN: Gentamycin, IPM: Imipenem, MRP: Meropenem, PTZ: Piperacillin-Tazobactam, AK: Amikacin, P: Penicillin, CIP: Ciprofloxacin, VA: Vancomycin, TE: Teicoplanin, LZ: Linezolid, CTZ: Ceftazidime; COX: Cloxacillin, DA: Clindamycin, E: Erythromycin, COT: Cotrimoxazole, CXM: Cefixime, CN: Gentamycin, AMC: Amoxyclave.
E. coli was the most commonly organism (62.8\% of all 113 isolates) among all of the meat samples, followed by Enterococcus $(14.1 \%)$ and Klebsiella (11.5\%). Interestingly, a total of 5 MRSA strains were isolated. On the contrary, a similar study done on raw meats (from chicken, goat, buffalo and pork) showed higher prevalence of Staphylococcus aureus (68\% of all the samples) instead, while E. coli was second most isolated organism (54\% of all the samples) ${ }^{25}$ However, the study in Bhaktapur had E. coli as the most commonly isolated organism, in line to our study. ${ }^{22}$ Nevertheless, the presence of micro-organisms such as $E$. coli indicate towards high risk of infection from foodborne diseases when raw meat dishes are consumed or when undercooked meat products are consumed.

Furthermore, when multidrug resistant (MDR) pattern was observed, there were total of 31 MDR E. coli in all samples, 13 MDR Klebsiella pneumoniae, 2 MDR Enterobacter and 1 MDR Citrobacter. This corroborates to $43.6 \%$ of all isolated $E$. coli being multidrug resistant, all of the isolated Klebsiella, all of the isolated Enterobacter and $25 \%$ of all isolated Citrobacter to be multidrug resistant. In a similar study done in buffalo meat and chicken meat from Bhaktapur, $52.5 \%$ of the isolated E. coli were MDR followed by $77.7 \%$ Staphylococcus aureus. $^{22}$ However, another study done on chicken meat in Kathmandu did not find any MDR isolates. ${ }^{26}$

When individual isolates were investigated, $E$. coli was found to be most resistant to Ampicillin (AMP). $81.6 \%$ of all E. coli isolates $(\mathrm{n}=71)$ showed resistance to AMP. A similar study done in chicken meat from Kathmandu Valley showed that $100 \%$ of isolated E. coli were resistant to AMP. ${ }^{26}$ Similarly, in our study, $60.5 \%$ of all $E$. coli isolates showed resistance to Ciprofloxacin, while the other study has reported $3 \%$ of Ciprofloxacin resistant E. coli and have not reported any MDR. ${ }^{26}$ Interestingly, all Enterobacter isolates $(\mathrm{n}=2)$ were resistant to AK, AMP, CFP, CIP, CN, CTR, CTZ, IPM, LZ and TZP, while only one of them was resistant to SCF. However, there were only two isolates to investigate this antibiotic resistance pattern. Among the Enterobacteriaceae family (E. coli, Enterobacter, Klebsiella and Citrobacter) the most resistance was observed against Ampicillin (83.3\%), followed by Ciprofloxacin (64.4\%), Gentamycin 
(58.8\%), Ceftazidime (38.8\%), with the lowest resistance against Sulbactam/Cefoperazone (3.3\%). Among the Enterococci, the most resistance was observed against Penicillin (25\%). Similarly, Staphylococcus was equally resistant $(42.8 \%)$ against AMC, CIP, COT, COX, CXM, DA, E, CN and $\mathrm{P}$, while being comparatively less resistant $(28.5 \%)$ to $\mathrm{LZ}$.

Due to time and financial constraints, all of the meat selling vendors were not included in the study. This study depicts a representative data, from Banepa and Dhulikhel Municipality, on bacteria and their antimicrobial resistance patter in meat products.

\section{CONCLUSION}

From this study, it was clear that the meat vendors lack hygiene, as only two sites were without any pathogenic isolates. From the results of our study, the conclusion on which type of meat is safe to consume, is ambiguous. This argument should only be pursued with investigation results from higher number of samples, including additional collection sites.

Nevertheless, the meat samples were mostly infested with $E$. coli, which showed resistance towards Ampicillin followed by Ciprofloxacin. Interestingly, all of Klebsiella and Enterobacter isolates showed multidrug resistant characteristic, while only about half of all E. coli were multidrug resistant.

As this study aimed to investigate the presence of bacterial isolates in meat and their AMR pattern, further study is required to understand the direct and indirect effects of the presence of multidrug resistant isolates to human health. Nevertheless, the presence of MDR isolates indicates the misuse of antibiotics in farm or vendor level. Therefore, we recommend for more controlled use of antibiotics in animal rearing industry as well as more hygienic environment at meat selling shops.

\section{CONFLICT OF INTEREST}

None declared

\section{ACKNOWLEDGEMENT}

We express our gratitude towards the meat vendors who provided with the samples for our study.

\section{REFERENCES}

1. Odeyemi OA and Sani NA. Antibiotic resistance and burden of foodborne diseases in developing countries. Future Sci OA. 2016; 2(4): FSO139.

2. Hashempour-Baltork F, Hosseini H, ShojaeeAliabadi S, Torbati M, Alizadeh AM, Alizadeh M. Drug Resistance and the Prevention Strategies in Food Borne Bacteria: An Update Review. Adv Pharm Bull. 2019; 9(3):335-347.

3. O'Neill J. Tackling a global health crisis: initial steps. Review on Antimicrobial Resistance. 2015.

4. Ramdam N. Study of antimicrobial use pattern, residue and resistance in poultry of Nepal. (M.V.Sc. Pharmacology thesis). Agriculture and Forestry University, Rampur, Nepal, 2015.

5. Van Boeckel T.P, Brower C, Gilbert M, Grenfell B.T, Levin SA, Robinson TP, Teillant A, Laxminarayan R. Global trends in antimicrobial use in food animals. Proc. Natl. Acad. Sci. USA. 2015; 112, 5649-5654.

6. World Health Organization (WHO). Antimicrobial Resistance. 2017. Available: https://www.who.int/ health-topics/antimicrobial-resistance

7. Kalam MA, Alim MA, Shano S, et al. Knowledge, Attitude, and Practices on Antimicrobial Use and Antimicrobial Resistance among Poultry Drug and Feed Sellers in Bangladesh. Vet. Sci. 2021.8 (111).

8. Mdegela RH, Mwakapeje ER, Rubegwa B. Antimicrobial Use, Residues, Resistance and Governance in the Food and Agriculture Sectors, Tanzania. 2021: 10(454).

9. Nonga H.E, Muhairwa AP, Prevalence and antibiotic susceptibility of thermophilic Campylobacter isolates from free-range domestic duck (Cairinamoschata) in Morogoro municipality, Tanzania. Trop Anim. Health Pro. 2010; 42: (165-172)

10. Nonga HE, Mariki M, Karimuribo ED, Mdegela RH. Assessment of Antimicrobial Usage and Antimicrobial Residues in Broiler Chickens in Morogoro Municipality, Tanzania. Pak. J. Nutr. 2009; 8: 203-207

11. Mensah SE, Koudande OD, Sanders P, Laurentie M, Mensah GA, Abiola FA. Antimicrobial residues in foods of animal origin in Africa: public health risks. Rev Sci Tech. 2014; 33(3): 987-96.

12. Tollefson L and Karp BE. Human health impact from antimicrobial use in food animals. Med Mal Infect. 2004; 34(11): 514-521.

13. Painter JA, et al. Attribution of foodborne illnesses, hospitalizations, and deaths to food commodities by using outbreak data, United States, 1998-2008. Emerg. Infect. Dis. 2013; 19: 407-415.

14. Scallan Em et al. Foodborne illness acquired in the United States-major pathogens. Emerg. Infect. Dis. 2011; 17:7-15.

15. National Research Council. The Effects on Human Health of Subtherapeutic Use of Antimicrobials in Animal Feeds. Washington, DC: The National Academies Press. 1980. Available: https:// doi.org/10.17226/21

16. Nepal Agritech. Nepal Agritech 2017 Expo. 2017. Available: http://nepalagritech.com.np/events/nepalpoultry-livestock-2017/

17. Koirala A, Bhandari P, Shewade HD, Tao W, Thapa B, Terry R, Zachariah R, Karki S. Antibiotic Use in Broiler Poultry Farms in Kathmandu Valley of Ne- 
pal: Which Antibiotics and Why?. Tropical Med and Infect. Dis. 2021; 6(2):47.

18. Lambrou AS, Innes GK, O’Sullivan L. et al. Policy implications for awareness gaps in antimicrobial resistance (AMR) and antimicrobial use among commercial Nepalese poultry producers. Glob Health Res Policy 6. 2021; 6.

19. Acharya KP, Wilson RT. Antimicrobial Resistance in Nepal. Frontiers in Medicine. 2019; 6.

20. Subedi KP. An Assessment of Good Hygienic Practices of Broiler Value Chain of Kaski District of Nepal. 2013. [Accessed: 29 July 2021] Available: https:/edepot.wur.nl/279019

21. Shrestha A, Bajracharya AM, Subedi H. et al. Multi -drug resistance and extended spectrum beta lactamase producing Gram negative bacteria from chicken meat in Bharatpur Metropolitan, Nepal. BMC Res Notes. 20171; 10: 574.

22. Saud B, Paudel G, Khichaju S, Bajracharya D, Dhungana G, Awasthi MS, Shrestha V MultidrugResistant Bacteria from Raw Meat of Buffalo and Chicken, Nepal. Vet Med Int. 2019; 2019: 7960268.

23. Magiorakos, AP, et al. Multidrug-resistant, extensively drug-resistant and pandrug-resistant bacteria: an international expert proposal for interim standard definitions for acquired resistance. Clin Microbiol Infect 2012; 18: 268-281.

24. Clinical and Laboratory Standards Institute. CLSI Standards: Guidelines for Health Care Excellence. Available: https://clsi.org/standards/

25. Bantawa K, Rai K, Limbu DS, Khanal H. Foodborne bacterial pathogens in marketed raw meat of Dharan, eastern Nepal. BMC Res Notes 2018; 11: 618

26. Gautam N, Poudel R, Lekhak B, Upreti, M. Antimicrobial Susceptibility Pattern of Gram-Negative Bacterial Isolates from Raw Chicken Meat Samples. Trib. Univ Journal Micro. 2019; 6:89-95. 